\title{
Solar PV parameter estimation using multi-objective optimisation
}

\author{
Nikita Rawat, Padmanabh Thakur, Utkarsh Jadli
}

Department of Electrical Engineering, Graphic Era Deemed to be University, India

\begin{tabular}{l}
\hline \hline Article Info \\
\hline Article history: \\
Received Aug 20, 2018 \\
Revised Jan 7, 2019 \\
Accepted May 28, 2019 \\
\hline
\end{tabular}

\section{Keywords:}

Multi-objective optimisation, Solar PV

Particle swarm optimisation

Newton-Raphson

NSGA-II

\begin{abstract}
The estimation of the electrical model parameters of solar PV, such as light-induced current, diode dark saturation current, thermal voltage, series resistance, and shunt resistance, is indispensable to predict the actual electrical performance of solar photovoltaic (PV) under changing environmental conditions. Therefore, this paper first considers the various methods of parameter estimation of solar PV to highlight their shortfalls. Thereafter, a new parameter estimation method, based on multi-objective optimisation, namely, Non-dominated Sorting Genetic Algorithm-II (NSGA-II), is proposed. Furthermore, to check the effectiveness and accuracy of the proposed method, conventional methods, such as, 'Newton-Raphson', 'Particle Swarm Optimisation, Search Algorithm, was tested on four solar PV modules of polycrystalline and monocrystalline materials. Finally, a solar PV module photowatt PWP201 has been considered and compared with six different state of art methods. The estimated performance indices such as current absolute error matrics, absolute relative power error, mean absolute error, and P-V characteristics curve were compared. The results depict the close proximity of the characteristic curve obtained with the proposed NSGA-II method to the curve obtained by the manufacturer's datasheet.
\end{abstract}

Copyright $@ 2019$ Institute of Advanced Engineering and Science. All rights reserved.

\section{Corresponding Author:}

Nikita Rawat,

Department of Electrical Engineering,

Graphic Era Deemed to be University,

566/6 Bell Road, Society Area, Clement Town Dehradun, Uttarakhand, India.

Email: nikitarwt8@gmail.com

\section{INTRODUCTION}

Among all the available inexhaustible energy sources, solar PV systems have received utmost attention throughout the world because of their abundance, lack of pollution, zero noise, and less maintenance characteristics and their wide acceptance in integration with modern power grids [1]. Though, solar energy is being considered as the most accessible renewable energy resources with huge potential of electricity generation, unfortunately, it is often characterized by low power density, low conversion efficiency and high installation costs [2]. Therefore, there is need to explore the research in the area that could be supportive in enhancement of optimal capturing capacity of available solar energy. Over the years, myriad of works have been carried out to ensure improved performance of the solar PV. Among all of the existing research areas the parameter estimations and modeling of solar PV have received utmost attentions by the researchers.

The accurate estimation of electrical model parameters, such as, light-induced current $\left(I_{P h}\right)$, diode dark saturation current $\left(I_{o}\right)$, thermal voltage $\left(V_{T}\right)$, series resistance $\left(R_{s}\right)$, and shunt resistance $\left(R_{p}\right)$, of solar PV is necessary for accomplishing the following motives:

a. To improve the overall efficiency of PV systems [3].

b. To predict expected power output in varying environmental condition [4]. 
c. To obtain accurate design specification of the power conditioning equipment connected with the solar $\mathrm{PV}$, and [5].

d. To simulate maximum power tracking algorithm, precisely.

Generally, existing methods were divided into three categories in the research, such as: Analytical methods, Numerical methods, and Metaheuristics methods.

Usually, the manufacturer provides the remarkable points, such as, "voltage at the maximum power point $\left(V_{M P}\right)$ ', 'current at the maximum power point $\left(I_{M P}\right)$ ', 'short-circuit current $\left(I_{S C}\right)$, and 'open-circuit voltage $\left(V_{O C}\right)$ ' in their data sheet [6]. The accuracy of parameter estimation through analytical methods relies heavily on the accurate emplacement of these remarkable points or known parameters on solar PV output characteristics $[3,7]$.

Among the various existing numerical methods, Newton-Raphson (NR) method [8], Lambert W function [9], and Gauss-Seidel (GS) method [10], were frequently considered in estimation of accurate electrical parameters of solar PV. Though these numerical methods have a higher level of accuracy than the analytical methods, these methods suffer from extensive computation time for the convergence also they converge to local maxima instead of global in case of wrong selection of initial values especially in NR and GS methods $[8,11]$.

Although Metaheuristics Algorithms based approaches play a vital role in the extraction of electrical model parameters of solar PV, unfortunately, the speed of convergence is found to be low in genetic algorithm (GA) [3]. Also, the GA based approach is found to be unsuitable for highly interactive fitness function [3]. The swap between the initial temperature and cooling schedule is a major issue in simulating annealing (SA) [12]. Though particle swarm optimization (PSO) outperforms SA and GA [13], at the same time it is found inept to track accurate characteristics as provided in manufacturer's datasheet. Also, the uniformity of estimated electrical model parameter cannot be assured through PSO [3, 13-15].

Besides the shortfalls as discussed above, most of the aforementioned methods consider the task of parameter estimations as a single objective optimisation i.e., the error between the real and estimated or predicted current at a known voltage is considered as the objective function. Indeed, parameter estimation of solar PV is a multi-objective optimisation (MOO) task, wherein, accurate values of all five parameters, such as $I_{P h}, I_{o}, V_{T}, R_{s}$, and $R_{p}$ are highly desirable to achieve characteristics exactly in tune with the real characteristics of solar PV. Unfortunately, in most of the research works, all of these five unknown parameters were not considered to reduce computational complexities.

Therefore, to rectify the inconsistencies prevailing in these methods, the present study proposes an accurate method of parameters extraction based on MOO [16], to accurately describe the solar PV output characteristics.

\section{THE SOLAR PV CELL MODEL}

The single diode model or $R_{p}$-model of solar PV is shown in Figure 1 which has been used in the present work to investigate the performance of solar PV. Although, there are two and three diode models of solar PV but these models have simultaneously increased the computational complexity due to a large number of unknown parameters. Also, a significant trade-off between accuracy and computational simplicity is achieved in $R_{p}$-model [11].

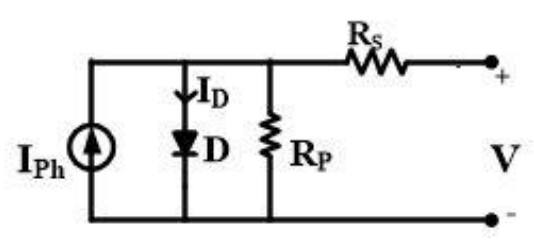

Figure 1. Single-diode solar PV model

The characteristic equation of $R_{p}$-model, as given in (1), provides the relation between the output voltage $(V)$ and current $(I)$ in terms of unknown parameters.

$$
I=I_{P h}-I_{o}\left[\exp \left(\frac{V+R_{s} I}{V_{T}}\right)-1\right]-\frac{V-R_{s} I}{R_{p}}
$$


Where, $V_{T}=\left(\alpha K T N_{s}\right) / e$ is in terms of diode ideality factor $(\alpha)$, electron charge $(e)$, Boltzmann's constant $(K)$, number of solar PV cell in series $\left(N_{s}\right)$, and temperature $(T)$.

\section{PROPOSED OBJECTIVE FUNCTION}

The output characteristic of a PV cell relies on five parameters, namely, $I_{P h}, I_{o}, V_{T}, R_{s}$, and $R_{p}$, as given in (1). To estimate these unknown parameters, five equations, as given in (2), (3), (4), (6), and (8), can be derived from (1) as [17]:

a. Under short circuit condition, i.e., when $V=0, I=I_{S C}$, the relation, as given in (1), can be written as:

$$
f_{1}(x)=I_{S C}-I_{P h}+I_{o}\left(\exp \left(\frac{I_{S C} R_{S}}{V_{T}}\right)-1\right)+\frac{I_{S C} R_{S}}{R_{P}}
$$

b. Under open circuit condition, i.e., when $I=0, V=V_{O C}$, the relation as given in (1), can be derived as:

$$
f_{2}(x)=I_{P h}-I_{o}\left(\exp \left(\frac{V_{O C}}{V_{T}}\right)-1\right)-\frac{V_{O C}}{R_{p}}
$$

c. At maximum power point (MPP), i.e., when $I=I_{M P}, V=V_{M P}$, the relation, as given in (1), can be written as:

$$
f_{3}(x)=I_{M P}-I_{P h}+I_{o}\left(\exp \left(\frac{V_{M P}+I_{M P} R_{s}}{V_{T}}\right)-1\right)+\frac{\left(V_{M P}+I_{M P} R_{S}\right)}{R_{P}}
$$

d. The slope at MPP on $P-V$ curve will be parallel to the voltage axis and hence it is found that

$$
\left.\frac{d I}{d V}\right|_{M P P}=-\frac{I_{M P}}{V_{M P}}
$$

On solving (5) the forth equation can be derived as:

$$
f_{4}(x)=I_{M P}-\left(V_{M P}-I_{M P} R_{s}\right)\left(\frac{I_{o}}{V_{T}} \exp \left(\frac{V_{M P}+I_{M P} R_{s}}{V_{T}}\right)+\frac{1}{R_{P}}\right)
$$

e. The final equation is derived by calculating the slope of the $I-V$ characteristic curve. The slope of the $I$ - $V$ characteristic curve is derived by differentiating the output current with respect to the output voltage under short circuit condition.

$$
\left.\frac{d I}{d V}\right|_{I=I_{S C}}=-\frac{1}{R_{p}}
$$

On solving (7) the fifth equation can be derived as:

$$
f_{5}(x)=\frac{R_{s}}{R_{p}}-\frac{I_{o}}{V_{T}} \exp \left(\frac{I_{S C} R_{s}}{V_{T}}\right)\left(R_{p}-R_{s}\right)
$$

The (2), (3), (4), (6), and (8), have been combined to define objective function, $f(x)$, as:

$$
f(x)=\left[f_{1}(x), f_{2}(x), f_{3}(x), f_{4}(x) f_{5}(x)\right]
$$

Now, the MOO problem is formulated as:

$$
\min \left(f_{1}(x), f_{2}(x), f_{3}(x), f_{4}(x), f_{5}(x)\right)
$$


Here, $x$ is the array of decision variables $\left\{x_{1}, x_{2}, x_{3}, x_{4}, x_{5}\right\}$. In the proposed work $x_{1}, x_{2}, x_{3}, x_{4}$, and $x_{5}$ represents $I_{P h}, I_{o}, R_{s}, R_{p}$ and $V_{T}$ respectively.

\subsection{Proposed parameter estimation method}

Various MOO methods generated from GA, such as the Vector-Evaluated Genetic Algorithm, Strength Pareto Metaheuristics Algorithm, Pareto Archived Evolution Strategy, classical non-dominated sorting-based multi-objective evolutionary algorithm, and NSGA-II, were tested and verified. Among these Methods, NSGA-II is considered to be one of the best methods due to its lower computation time and non-elitism approach. Therefore the present work considers NSGA-II, to evaluate the electrical model parameters of solar PV [16]. The following steps have been used in the proposed NSGA-II:

a. Initialisation: objective function $f(x)$, as given in (9), main population $D$, and the input variable and their ranges are initialized.

b. Non-Domination Sort: NSGA-II uses non-domination sort to sort the initialized main population $D$. Each individual $p$ in the main population $D$ has two sets. The set $S_{p}$ contains the individuals which are dominated by $p$ whereas set $n_{p}$ contains those individuals which are dominated to $p$. If the individual $p$ has zero individuals in its set $n_{p}$, then $p$ is assigned to front one $\left(F_{l}\right)$ and ranked one.

c. Crowding Distance: As the fitness value or rank is achieved, the next step is to assign the crowding distance $F_{i}\left(d_{j}\right)$, where $F_{i}$ is the $i^{\text {th }}$ front counter and $d_{j}$ is the crowding distance of the $j^{\text {th }}$ individual in front $F_{i}$. The crowding distance is the distance between two individuals.

d. Tournament Selection: The selection of the individual is dependent on its individual rank and crowding distance. The rank of the individual has been checked and the individual with the smallest rank is selected. In case of similar rank of two individuals, the crowding distance is considered for the selection. In this case, the individual with larger values of crowding distance, i.e., $F_{i}\left(d_{j}\right)$, is selected.

e. Genetic Operators: Offspring population is created using the genetic operator's binary crossover and mutation.

f. Recombination: The parent population is united with the offspring population and sorted again using non-domination sorting. The unfit individuals are replaced by the fit one and the original size of the population is maintained.

\section{RESULTS AND DISCUSSION}

\subsection{Estimation of performance indices for polycrystalline and monocrystalline PV modules}

Three polycrystalline and monocrystalline PV module with specifications as given in Tong NT et al [18] were considered. For proposed method and PSO, similar lower and upper bound values were taken, while for the NR method, different initial values were used. The electrical model parameters value for the PV modules found by the proposed method, NR, PSO, and search algorithm is summarised in Table 1. Figure 2-5 shows the $P-V$ characteristic of the PV modules. It is evident that the $P-V$ curve obtained by the proposed method for both type of PV cell modules were closest to the MPP. Also, it was observed that NR was the second best among the other methods but the accuracy of NR method is very much subjected to the selection of initial values which is evident from Table 1. Table 2 summarises the ARPE calculated for PV modules. The ARPE for all the PV modules using the proposed method were calculated to be very less. Thus, from the analysis of all the results it is evident that proposed method outperforms NR, PSO, and search algorithm in the case of polycrystalline as well as monocrystalline PV modules.

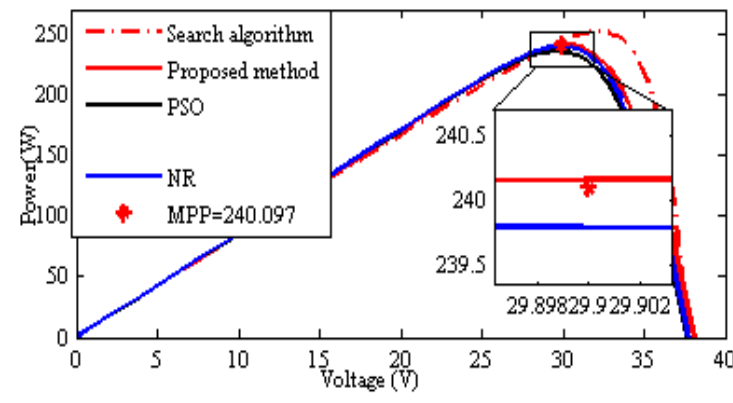

Figure 2. $P-V$ characteristics for WW energy, AS240-6P30 module

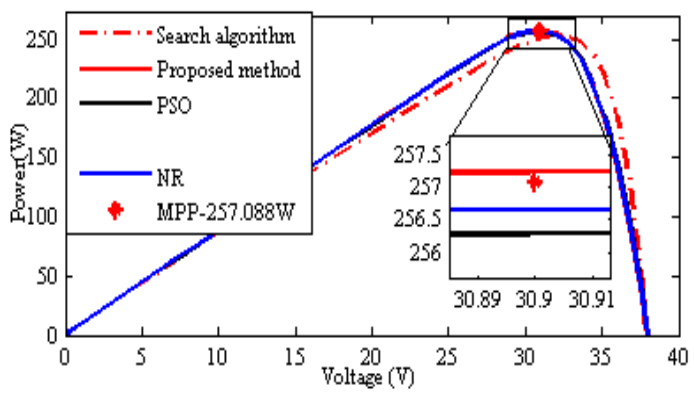

Figure 3. $P-V$ characteristics for Solarworld, Pro. SW255 module 


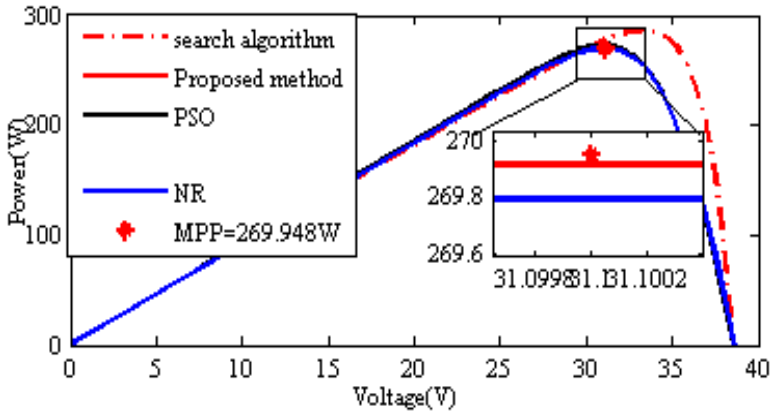

Figure 4. $P-V$ characteristics for Nemy, JP270M60 module

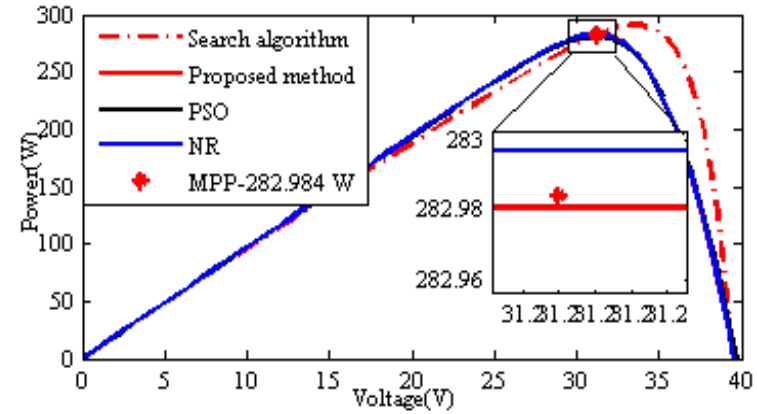

Figure 5. $P-V$ characteristics for Solarworld, Plus SW280 module

Table 1. Extracted parameters for polycrystalline and monocrystalline PV modules by the proposed and existing methods

\begin{tabular}{|c|c|c|c|c|c|c|c|c|}
\hline PV modules & $\begin{array}{c}\text { ParameterE } \\
\text { xtracted }\end{array}$ & $\begin{array}{c}\text { Search } \\
\text { algorithm } \\
{[18]}\end{array}$ & $\begin{array}{c}\text { Initial } \\
\text { value }\end{array}$ & $\begin{array}{l}\text { Estimated } \\
\text { value }\end{array}$ & $\begin{array}{l}\text { Lower } \\
\text { Bound }\end{array}$ & $\begin{array}{c}\text { Upper } \\
\text { Boun } \\
\mathrm{d} \\
\end{array}$ & PSO & $\begin{array}{c}\text { Proposed } \\
\text { method }\end{array}$ \\
\hline \multicolumn{9}{|l|}{ Polycrystalline } \\
\hline \multirow{5}{*}{$\begin{array}{l}\text { WW Energy } \\
\text { AS240-6P30 }\end{array}$} & $I P h(A)$ & 8.5705 & 8.5 & 8.5707 & 8 & 8.6 & 8.5568 & 8.5108 \\
\hline & Io $(A)$ & $0.0074 \mathrm{E}-6$ & $1 \mathrm{E}-8$ & $6.83 \mathrm{E}-9$ & $7 \mathrm{E}-10$ & $1 \mathrm{E}-7$ & $3.488 \mathrm{E}-8$ & $1 \mathrm{E}-8$ \\
\hline & $R s(\Omega)$ & $5.79 \mathrm{E}-3$ & 0.3 & 0.3490 & 0.1 & 0.5 & 0.3450 & 0.343 \\
\hline & $R p(\Omega)$ & 94.87 & 2000 & 4175.46 & 50 & 5000 & 2047.8 & 3500.6 \\
\hline & $V T$ & $\alpha=1.1725$ & 1.6 & 1.7997 & 0.1 & 2 & 1.9489 & 1.8509 \\
\hline \multirow{5}{*}{$\begin{array}{l}\text { Solarworld, } \\
\text { Pro. SW255 }\end{array}$} & $I P h(A)$ & 8.8805 & 8 & 8.8807 & 8 & 9 & 8.8565 & 8.8814 \\
\hline & Io $(A)$ & $0.026 \mathrm{E}-6$ & $1 \mathrm{E}-6$ & $2.317 \mathrm{E}-8$ & $10 \mathrm{E}-10$ & $1 \mathrm{E}-6$ & $2.311 \mathrm{E}-8$ & $0.1 \mathrm{E}-7$ \\
\hline & $R s(\Omega)$ & $3.457 \mathrm{E}-3$ & 0.1 & 0.21 & 0.1 & 0.5 & 0.2093 & 0.2277 \\
\hline & $R p(\Omega)$ & 57.40 & 2000 & 2570.3 & 50 & 5000 & 2579.5 & 3735.8 \\
\hline & $V T$ & $\alpha=1.2554$ & 1 & 1.9228 & 0.1 & 2 & 1.9237 & 1.8422 \\
\hline \multicolumn{8}{|l|}{ Monocrystalline } & 9.6945 \\
\hline \multirow{4}{*}{$\begin{array}{c}\text { Solarworld, Plus } \\
\text { SW280 }\end{array}$} & $I_{o}(A)$ & $0.019 \mathrm{E}-6$ & $1 \mathrm{E}-8$ & $1.735 \mathrm{E}-8$ & $1 \mathrm{E}-10$ & $1 \mathrm{E}-7$ & $1.844 \mathrm{E}-8$ & $0.9 \mathrm{E}-8$ \\
\hline & $R_{s}(\Omega)$ & $5.357 \mathrm{E}-3$ & 0.2 & 0.3235 & 0 & 0.5 & 0.3447 & 0.3371 \\
\hline & $R_{p}(\Omega)$ & 61.07 & 2000 & 2714.3 & 50 & 1000 & 2591.2 & 3563.3 \\
\hline & $V_{T}$ & $\alpha=1.2793$ & 1.8 & 1.9612 & 0.1 & 2 & 1.9746 & 1.8991 \\
\hline \multirow{5}{*}{$\begin{array}{l}\text { Nemy, } \\
\text { JP270M60 }\end{array}$} & $I_{P h}(A)$ & 9.2002 & 9 & 9.2003 & 9 & 10 & 9.3243 & 9.2035 \\
\hline & $I_{o}(A)$ & $0.001 E-6$ & $1 E-9$ & $1.197 \mathrm{E}-9$ & $1 \mathrm{E}-10$ & $1 \mathrm{E}-7$ & $1.069 \mathrm{E}-9$ & $1 \mathrm{E}-9$ \\
\hline & $R_{s}(\Omega)$ & $5.01 \mathrm{E}-3$ & 0.3 & 0.3015 & 0.1 & 0.5 & 0.2981 & 0.3061 \\
\hline & $R_{p}(\Omega)$ & 207.73 & 9000 & 9120.8 & 1000 & 10000 & 9393.7 & 9838.8 \\
\hline & $V_{T}$ & $\alpha=1.1027$ & 1.6 & 1.6958 & 0.1 & 2 & 1.6826 & 1.6827 \\
\hline
\end{tabular}

Table 2. Absolute relative power error for polycrystalline modules

\begin{tabular}{|c|c|c|c|c|c|c|}
\hline PV module & $\begin{array}{l}\text { Extraction } \\
\text { methods }\end{array}$ & $\begin{array}{l}\text { Actual Maximum } \\
\text { Power } P_{\text {actual }}(W)\end{array}$ & $\begin{array}{c}\text { Calculated } \\
\text { maximum power } \\
P_{\text {cal }}(W)\end{array}$ & $\begin{array}{l}\text { Absolute } \\
\text { ARPE }=\end{array}$ & $\begin{array}{r}\text { Relative Po } \\
=\left|\frac{P_{\text {actual }}-P_{c a l}}{P_{\text {actual }}}\right|\end{array}$ & $\begin{array}{l}\times 100(\%) \\
\times \text { wer Error }\end{array}$ \\
\hline \multirow{4}{*}{$\begin{array}{l}\text { WW Energy } \\
\text { AS240-6P30 }\end{array}$} & NR & 240.097 & 239.8 & \multicolumn{3}{|c|}{$1.2370 \times 10^{-1}$} \\
\hline & PSO & 240.097 & 235.64 & \multicolumn{3}{|c|}{$0.0185 \times 10^{2}$} \\
\hline & Search algorithm & 240.097 & 243.3 & \multicolumn{3}{|c|}{$0.0133 \times 10^{2}$} \\
\hline & Proposed Method & 240.097 & 240.15 & \multicolumn{3}{|c|}{$2.2074 \times 10^{-2}$} \\
\hline \multirow{4}{*}{$\begin{array}{l}\text { Solarworld, Pro. } \\
\text { SW255 }\end{array}$} & NR & 257.088 & 256.76 & \multicolumn{3}{|c|}{$1.2758 \times 10^{-1}$} \\
\hline & PSO & 257.088 & 256.280 & \multicolumn{3}{|c|}{$3.1428 \times 10^{-1}$} \\
\hline & Search algorithm & 257.088 & 250.68 & \multicolumn{3}{|c|}{$0.0249 \times 10^{2}$} \\
\hline & Proposed Method & 257.088 & 257.15 & \multicolumn{3}{|c|}{$2.4116 \times 10^{-2}$} \\
\hline \multirow{4}{*}{$\begin{array}{l}\text { Solarworld, Plus } \\
\text { SW280 }\end{array}$} & NR & 282.984 & 282.99 & \multicolumn{3}{|c|}{$2.1202 \times 10^{-3}$} \\
\hline & PSO & 282.984 & 281.24 & \multicolumn{3}{|c|}{$6.1628 \times 10^{-1}$} \\
\hline & Search Algorithm & 282.984 & 282.52 & \multicolumn{3}{|c|}{$1.6396 \times 10^{-1}$} \\
\hline & Proposed Method & 282.984 & 282.980 & \multicolumn{3}{|c|}{$1.4135 \times 10^{-3}$} \\
\hline \multirow{4}{*}{ Nemy, JP270M60 } & NR & 269.948 & 269.793 & \multicolumn{3}{|c|}{$5.7418 \times 10^{-2}$} \\
\hline & PSO & 269.948 & 272.94 & \multirow{2}{*}{\multicolumn{3}{|c|}{$\begin{array}{c}0.0110 \times 10^{2} \\
0.029 \times 10^{2}\end{array}$}} \\
\hline & Search Algorithm & 269.948 & 277.8 & & & \\
\hline & Proposed Method & 269.948 & 269.913 & \multicolumn{3}{|c|}{$1.2965 \times 10^{-2}$} \\
\hline
\end{tabular}




\subsection{Estimation of performance indices for photowatt PWP201 module}

The unknown parameters of Photowatt PWP201 comprising of 36 polycrystalline silicon series connected cells at $\mathrm{T}=45^{\circ} \mathrm{C}$ [18], is calculated with the proposed method (NSGA-II), NR, GA, PS, SA, (MPCOA), and (GOFPANM) are outlined in Table 3. Figure 6 shows the $P$ - $V$ curve of the PV module. The $P-V$ curve obtained by the proposed method is close to the experimental data, in particular at the MPP point. Further, the values of MPP and ARPE, as estimated with these existing and the proposed method, have been summarised in Table 4. The ARPE is smaller for the proposed method. Table 5 shows the IAE matrics for each experimentally measured I-V points. The MAE calculated for the proposed method is $0.1875 \%$, which is the lowest followed by the MAE calculated by the MPCOA and GOFPANM methods.

The convergence process of the proposed method is shown in Figure 7. The proposed method is incomplex and does not have parameters that need to be tuned as in the case of PSO, SA, PS, MPCOA, and GOFPANM methods.

Table 3. Photowatt PWP201 module parameters extracted by the proposed method and compared with various methods

\begin{tabular}{cccccccc}
\hline $\begin{array}{c}\text { Parameters } \\
\text { Extracted }\end{array}$ & SA [12] & NR [8] & PS [19] & GA [20] & MPCOA [21] & $\begin{array}{c}\text { GOFPANM } \\
{[22]}\end{array}$ & $\begin{array}{c}\text { Proposed } \\
\text { method }\end{array}$ \\
\hline$I_{P h}(A)$ & 1.0331 & 1.0318 & 1.0313 & 1.0441 & 1.03188 & 1.0305143 & 1.0301 \\
$I_{o}(\mu A)$ & 3.6642 & 3.2875 & 3.1756 & 3.436 & 3.3737 & 3.4822631 & 0.79851 \\
$R_{s}(\Omega)$ & 1.1989 & 1.2057 & 1.2053 & 1.1968 & 1.20295 & 1.2012710 & 1.4944 \\
$R_{p}(\Omega)$ & 8333.333 & 555.56 & 714.29 & 555.556 & 849.693 & 981.98232 & 785.1624 \\
$N_{s} \alpha$ & 48.8211 & 48.45 & 48.289 & 48.5862 & 48.5065 & 48.6428351 & 43.583919 \\
& & & & & & & \\
\hline
\end{tabular}

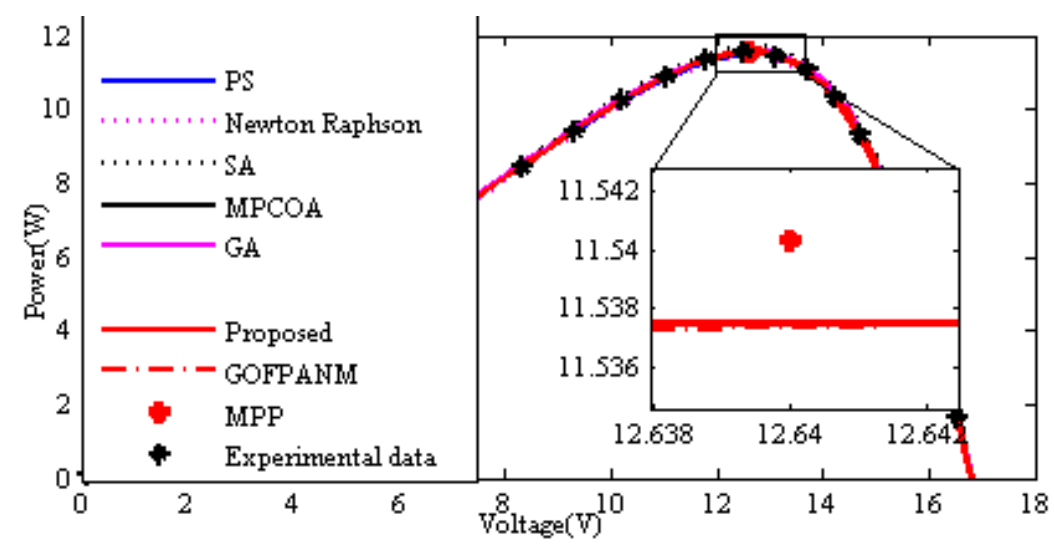

Figure 6. The P-V curve of the reference module Photowatt PWP201 by the proposed method and eight other existing method

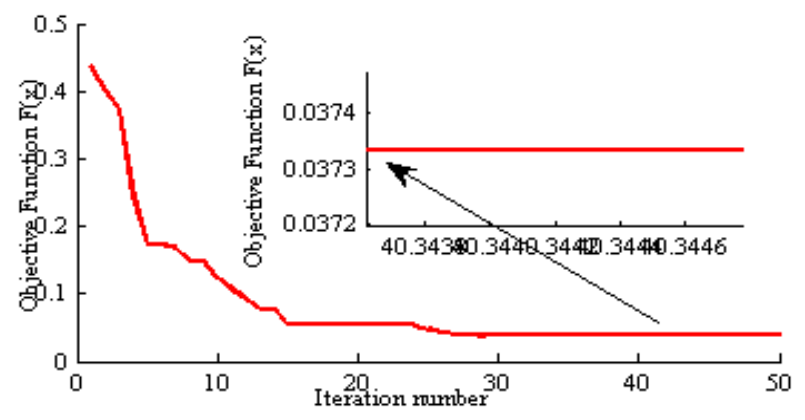

Figure 7. The convergence curve of Photowatt PWP201 by the proposed method $(f(x)=0.0373$ at 50 generation and 5000 population) 
Table 4. Absolute relative power error for Photowatt PWP201 module

\begin{tabular}{cccc}
\hline Methods & $* P_{\text {actual }}$ & $* * P_{\text {cal }}$ & ARPE \\
\hline SA & 11.5403 & 11.6958 & $0.01347 \times 10^{2}$ \\
NR & 11.5403 & 11.4441 & $8.60462 \times 10^{-1}$ \\
PS & 11.5403 & 11.5025 & $3.27547 \times 10^{-1}$ \\
GA & 11.5403 & 11.5752 & $3.02418 \times 10^{-1}$ \\
MPCOA & 11.5403 & 11.5293 & $9.53181 \times 10^{-2}$ \\
GOFPANM & 11.5403 & 11.5374 & $2.51293 \times 10^{-2}$ \\
Proposed & 11.5403 & 11.5375 & $2.42628 \times 10^{-2}$ \\
method & & \\
*Actual Maximum Power, $P_{\text {actual }}(W)$ & \\
$* *$ Calculated maximum power, $P_{\text {cal }}(W)$ &
\end{tabular}

Table 5. The error matrics measurement by the proposed method and other existing methods for Photowatt PWP201 module

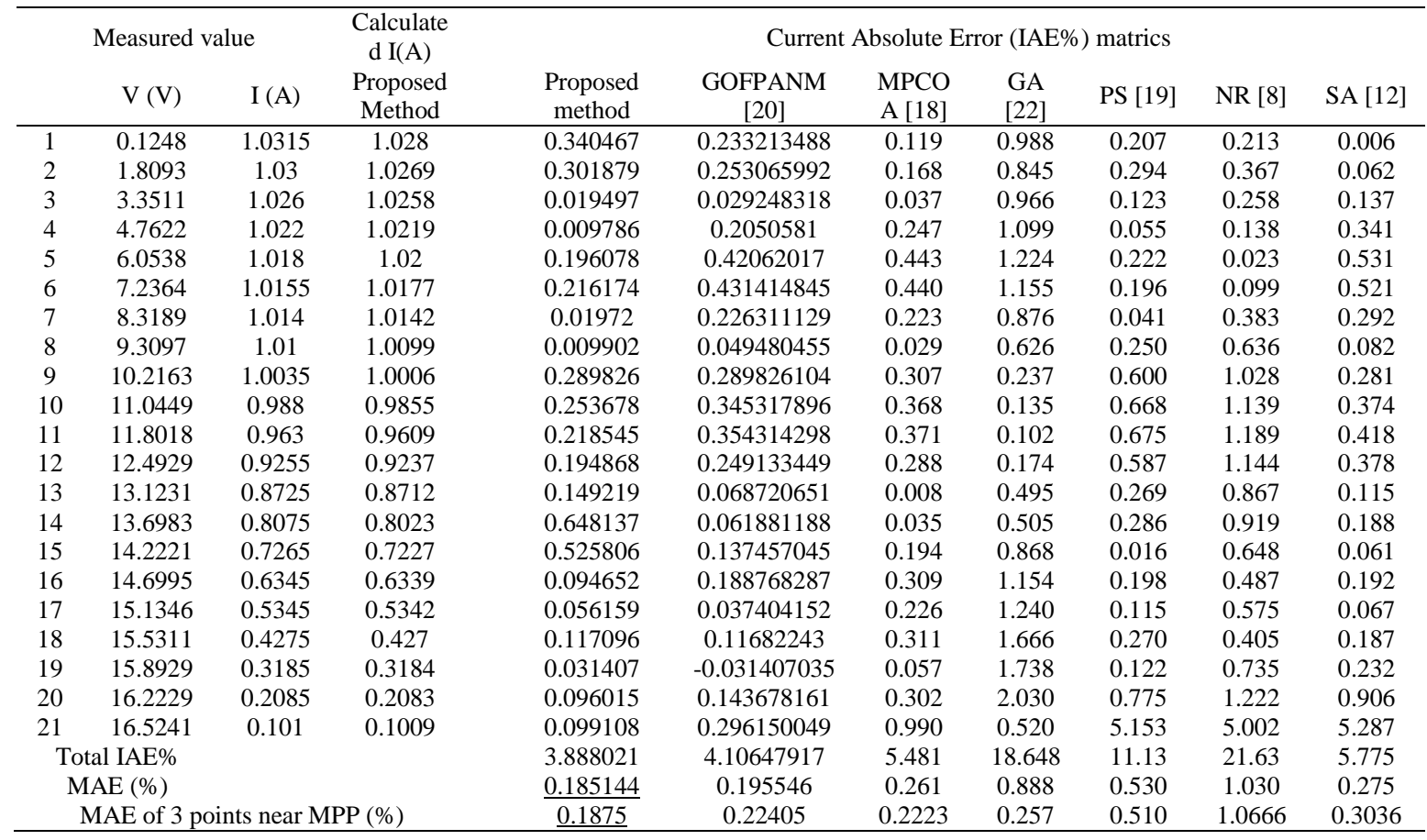

\section{CONCLUSION}

The present investigation has considered MOO algorithm NSGA-II for estimating the electrical model parameters of solar PV modules. In comparison to the existing methods such as NR, GA, PSO, PS, SA, MPCOA, and GOFPANM, the proposed NSGA-II method outperformed and provided a better $P-V$ and $I$ - $V$ curve, as well as a lesser value of ARPE and MAE. Henceforth, it is inferred that the MOO-based approach can be recommended as one of the most accurate tools for the parameters estimation of solar PV.

\section{REFERENCE}

[1] M. A. Jusoh, M. F. Tajuddin, S. M. Ayob \& M. A. Roslan., "Maximum Power Point Tracking RCharge Controller for Standalone PV System," Telkomnika (Telecommunication, Computing, Electronics and Control), vol. 16(4), pp. 1413-26, 2018.

[2] M. Mardlijah and Z. Zuhri. "Solar Panel Control System Using an Intelligent Control: T2FSMC and Firefly Algorithm," Telkomnika (Telecommunication Computing Electronics and Control), vol. 16(6), pp. 2988-2998, 2018.

[3] K. Ishaque, Z. Salam, S. Mekhilef \& A. Shamsudin., "Parameter extraction of solar photovoltaic modules using penalty-based differential evolution," Applied Energy, vol. 99, pp. 297-308, 2012.

[4] S. Shongwe and M. Hanif, "Comparative Analysis of Different Single-Diode PV Modeling Methods," in IEEE Journal of Photovoltaics, vol. 5, no. 3, pp. 938-946, May 2015.

[5] F. Attivissimo, A. Di Nisio, M. Savino and M. Spadavecchia, "Uncertainty Analysis in Photovoltaic Cell Parameter Estimation," in IEEE Transactions on Instrumentation and Measurement, vol. 61, no. 5, pp. 1334-1342, May 2012. 
[6] D. S. H. Chan and J. C. H. Phang, "Analytical methods for the extraction of solar-cell single- and double-diode model parameters from I-V characteristics," in IEEE Transactions on Electron Devices, vol. 34, no. 2, pp. 286-293, Feb. 1987.

[7] J. Accarino, G. Petrone, C. A. Ramos-Paja and G. Spagnuolo, "Symbolic algebra for the calculation of the series and parallel resistances in PV module model," 2013 International Conference on Clean Electrical Power (ICCEP), Alghero, 2013, pp. 62-66.

[8] T. Easwarakhanthan, J. Bottin, I. Bouhouch \& C. Boutrit., "Nonlinear minimization algorithm for determining the solar cell parameters with microcomputers," International Journal of Solar Energy, vol. 4(1), pp. 1-2, 1986.

[9] F. Ghani and M. Duke. "Numerical determination of parasitic resistances of a solar cell using the Lambert W-function," Solar Energy, vol. 85(9), pp. 2386-94, 2011.

[10] S. Shongwe and M. Hanif, "Gauss-Seidel iteration based parameter estimation for a single diode model of a PV module," 2015 IEEE Electrical Power and Energy Conference (EPEC), London, ON, 2015, pp. 278-284.

[11] M. G. Villalva, J. R. Gazoli and E. R. Filho, "Comprehensive Approach to Modeling and Simulation of Photovoltaic Arrays," in IEEE Transactions on Power Electronics, vol. 24, no. 5, pp. 1198-1208, May 2009.

[12] K. M. El-Naggar, M. R. AlRashidi, M. F. AlHajri \& A. K. Al-Othman., "Simulated annealing algorithm for photovoltaic parameters identification," Solar Energy, vol. 86(1), pp. 266-74, 2012.

[13] M. Ye, X. Wang \& Y. Xu., "Parameter extraction of solar cells using particle swarm optimization," Journal of Applied Physics, vol. 105(9), pp. 094502, 2009.

[14] K. Ishaque and Z. Salam. "An improved modeling method to determine the model parameters of photovoltaic (PV) modules using differential evolution (DE)," Solar energy, vol. 85(9), pp. 2349-59, 2011.

[15] J. J. Soon and K. Low, "Photovoltaic Model Identification Using Particle Swarm Optimization With Inverse Barrier Constraint," in IEEE Transactions on Power Electronics, vol. 27, no. 9, pp. 3975-3983, Sept. 2012.

[16] K. Deb, A. Pratap, S. Agarwal and T. Meyarivan, "A fast and elitist multiobjective genetic algorithm: NSGA-II," in IEEE Transactions on Evolutionary Computation, vol. 6, no. 2, pp. 182-197, April 2002.

[17] U. Jadli, P. Thakur and R. D. Shukla, "A New Parameter Estimation Method of Solar Photovoltaic," in IEEE Journal of Photovoltaics, vol. 8, no. 1, pp. 239-247, Jan. 2018.

[18] N. T. Tong and W. Pora. "A parameter extraction technique exploiting intrinsic properties of solar cells," Applied energy, vol. 15(176), pp. 104-15, 2016

[19] M. F. Al Hajri, K. M. El-Naggar, M. R. AlRashidi \& A. K. Al-Othman., "Optimal extraction of solar cell parameters using pattern search," Renewable Energy, vol. 44, pp. 238-45, 2012.

[20] M. R. Al Rashidi, M. F. Al Hajri, K. M. El-Naggar \& A. K Al-Othman., "A new estimation approach for determining the I-V characteristics of solar cells," Solar Energy, vol. 85(7), pp. 1543-50, 2011.

[21] Yuan X, Xiang Y \& He Y., "Parameter extraction of solar cell models using mutative-scale parallel chaos optimization algorithm," Solar Energy, vol. 108, pp. 238-51, 2014 Oct 1.

[22] S. Xu and Y. Wang, "Parameter estimation of photovoltaic modules using a hybrid flower pollination algorithm," Energy Conversion and Management, vol. 144, pp. 53-68, 2017. 